\section{UNIVERSITIES AND THE COMMUNITY}

$\mathrm{T}$

HAT public discussion on such a subject as "The Place of Universities in the Community" would range over a wide field was to be expected, and the one-day conference on that subject arranged by the British Association on May 10 at the University of Manchester proved no exception. The immediate purpose of the conference, to discuss important problems arising out of the projected expansion of the universities of Great Britain, tended at times to be overlooked by those who took part in the discussions at both sessions, and while the conference made some contribution to the education of public opinion as to what is involved in the expansion of the universities, particularly on the scientific side, little was added to what has already emerged in the debate between men of science and others on these questions, both before and after the appearance of the Barlow Report.

The first of the two sessions was devoted specifically to the consideration of the implications of the Barlow Report. Lord Simon of Wythenshawe, who presided over this session, did his best to keep the discussion on realistic lines but contented himself in his opening remarks with presenting the administrative background to the Barlow Report, pointing out that it was only one of a number of such official reports dealing with the question of capacity of the universities to provide the trained men and women which the community requires. He referred specifically to the earlier Goodenough, Teviot, McNair and Clapham Reports, and to the more recent Scarborough Report; but in view of what was said later by Prof. M. Polanyi, he might well also have cited the earlier Barlow Report on scientific staff. Lord Simon then quoted from the "Note on University Policy and Finance in the Decennium 1947-56" (which was discussed in Nature of April 12, p. 483), and emphasized the acceptance by the universities of the view that the Government has the right and the duty to satisfy itself that every field of study which in the national interest ought to be cultivated in Great Britain is in fact being adequately cultivated in the universities, and that the universities are using their resources with full regard both to efficiency and to economy. If the universities are collectively to devise and execute policies calculated to serve the national interest, the University Grants Committee would require strengthening, and Lord Simon referred to the recent appointment of a whole-time deputy chairman and to the Chancellor of the Exchequer's indication of the ultimate expansion of the grant to the universities to be administered by the Committee to at least $£ 16-£ 20$ millions as against $£ 2-£ 4$ millions before the War.

These figures were probably less effective in indicating what is immediately involved than Lord Simon's incidental remark that doubling the output of scientific workers within five years is a rate of expansion much greater than has ever been contemplated in the United States. The administrative and financial aspects were, however, scarcely again considered in the discussion. Prof. P. M. S. Blackett, who followed, thought that sufficient talent is available to provide the increased number of scientific workers required, and referred in particular to the reserve demand for such trained individuals represented by the teaching profession and by private industry, which probably needs more men of science than it recognizes. He urged that the Barlow Report should be followed by a further statistical inquiry into both the sources from which students enter the universities and the future of the graduates when they leave them.

One at least of these lines of thought was pursued by Dr. Eric James, high master of the Manchester Grammar School, who urged that the great weakness of the Barlow Report is that no evidence was taken from the schools as to their capacity to provide the requisite number of potential science graduates. He thought that the report made insufficient allowance for the number of trained science teachers required in the schools, on the quality of whose work in the schools, he maintained, the work of the universities rests. He urged that it should be a priority of the first order to discover where in the educational ladder the wastage of intelligence and talent occurs; emphasizing that we should remember that the educational system is a whole and not consider the universities apart from the schools, he pointed out that so far we have failed to formulate in any specific terms our ideas as to a general education for scientific workers.

This plea was later taken up by Sir John LennardJones. He urged that, as providing a link between the nation's intelligence and public affairs, the university has a duty to the State and should make a point of being fully and accurately informed as to the nation's need for trained workers, and moved a resolution which was seconded by Prof. J. D. Bernal and adopted at the end of the session. The resolution recommended to the Council of the British Association that the University Grants Committee be invited, in collaboration with the universities, (1) to make extensive factual surveys of the openings for graduates in the national life; (2) to maintain records of the careers of university graduates and the measure of their success in their professions; and (3) to publish periodic reports of the results of such surveys for the guidance of universities and schools. Whatever reservation individuals may have felt about the wisdom of asking the University Grants Committee to undertake this task-and misgivings were expressed in private if not publicly-the importance of university co-operation in appointments work was fully recognized, although no one pointed out that the Hankey Committee has already recommended that this work should be undertaken by the Higher Appointments Department of the Ministry of Labour.

Other points raised in the morning discussion were the age at which choice of a scientific career is usually determined, the detrimental effect of existing overcrowding and of the shortage of teaching staff. The importance of careful selection of students in university expansion and of encouraging adaptability and discouraging the intensive specialization which hinder mobility were noted. Mr. Ritchie Calder, commenting on the danger of middle-class unemployment, urged that greater emphasis should be placed on the regional character of the university; a position in which only 10 per cent of science graduates from Scottish universities find employment in Scotland is most unsatisfactory.

Opening the second session of the conference, which was to consider more specifically research and organisation, Sir Henry Dale, who presided, suggested that with the universities dependent on the Government for more than seventy-five per cent of 
their income, the influence of Government departments might become a serious factor in the expenditure of funds on research. Sir Henry Dale voiced once more the fears that he has often expressed that the war-time practice of the universities of carrying out research on subjects laid down by outside authorities might be perpetuated. He emphasized the vital importance of the universities maintaining, in Britain and elsewhere, their full independence, and reiterated that the proper function of the universities is to promote free research with no immediate objectives but to widen the boundaries of knowledge, in contradistinction to prescribed research undertaken for the particular end of solving an immediate practical problem.

No evidence was given during the meeting that either industry or the Government is offering research endowments to the universities to which restrictive or secrecy conditions are attached, and it is noteworthy that all recent reports on research and the universities which have recognized the increasing dependence of the universities on Government financial support have been confident of the ability of the universities to maintain their independence. Nevertheless, the afternoon session adopted the resolution moved by Sir Henry Dale recommending the Council of the British Association to make representations to the competent authorities of all universities in the British Empire, urging that under the normal conditions of peace no contract for research should be accepted by the scientific departments of any of these universities if its terms included any restriction on freedom of publication.

In their plea for a follow-up of the Barlow Report by an investigation of the educational ladder at the school stage, Prof. Blackett and Dr. James introduced the first new distinctive note; Prof. M. Polanyi struck the second. In a paper on the organisation of universities, without pursuing the secrecy theme, Prof. Polanyi spoke strongly for the univer. sities as the natural nurseries and homes of fundamental research. He recognizes the twin relations of teaching and research, and he pleaded that the advancement of learning depends on the universities being maintained as the well-springs of discovery. As Sir Henry Dale had said, it is the function of the university to hold aloft the search for truth in all its aspects; but when Prof. Polanyi added that it is waste of time to endow academic research workers unless the recipients are left free to use the funds at their own discretion, he gave expression to a principle which might well be re-considered by those industrial firms who have, as he indicated, tended to enter the academic field. Doubtless the distinction may not always be easy to maintain, but Prof. Polanyi equally insisted that the university itself should be careful not to be tempted into the investigation of practical problems which lie outside its own experience.

This most significant passage in Prof. Polanyi's paper was rather overlooked in the discussion, which seized, first on his reference to the importance of refusing to fill vacancies in senior appointments with men or women below a certain level of distinction and of not regarding too closely the special field of inquiry, even if this involves some over-crowded departments and others with chairs vacant in. definitely; and secondly, on his defence of some disparity between academic salaries and those of other professional positions in industry or elsewhere. Prof. Polanyi also maintained that unless society appreciates science for its own sake, it will not continue for long to cultivate genuine scientific research, and accordingly in the long run the universities depend for their existence on the recognition of cultural obligations by the nation. $\mathrm{He}$ also insisted that since it is impossible to recognize and subsidize all the growing points of science, the universities, which uphold the broad principle that their task is to supply individual creative minds with the opportunities to do the work of their own choice, cannot agree with the Vice-Chancellor's Committee that it is their function to plan to meet the whole range of national need for higher teaching and research.

Prof. Bernal did not altogether follow Prof. Polanyi in this view. His discussion of research was obviously coloured by his recent experience of war-time conditions, and he distinguished research as of two types: subjective research, which he agreed should be left to the universities, and the objective and prescribed research, distinguished by Sir Henry Dale. While subjective research is the proper function of the universities, Prof. Bernal insisted that the greater need is for a new type of research worker and director able to integrate this with other activities. He urged that social and economic problems can likewise be tackled on scientific lines; here he was obviously less concerned with the creative aspect and the freedom of choice stressed by Prof. Polanyi than with the question of organisation and the fact that the individual scientific worker might exercise his choice without adequate knowledge. He supported both the regional work of the university-regional contacts, he believes, will help to suggest continually fruitful problems for investigation by the universities, which should make it their business to discover the needs and problems of the region-and the cultural value of scientific research. We need a unitary culture which to-day must contain a scientific method, just as the experimental method would play a part in uniting knowledge. If an adequate social philosophy is not yet fully formed, we have at least learned that the whole approach to social problems as well as to physical problems should be scientific.

In a somewhat rambling discussion, little was said which had not already been ventilated in previous reports on the universities and research. Some points in that from the Association of Scientific Workers in particular were mentioned. The claims of social science as presented in the Clapham Report, and also of adult education, on the support of the universities were also emphasized. Dr. C. H. Desch referred to the changing outlook in the steel industry and to the demand for scientific workers for research and management positions in contrast to a demand merely for testing work, and to the way in which patents policy offsets the obsolete tendency to secrecy in industrial research. Commenting on the need for providing for the new growing points in science, Prof. Polanyi's suggestion that chairs should be left vacant found some support, Dr. Gordon observing that the universities should make it clear to the Government beforehand that they do not propose to retain inferior men in professorial chairs even if appointed on trial. His comment about differentiation in salary scales, however, was challenged; Prof. Polanyi had not denied that university salaries are in need of revision upwards; the scientific worker in a university should be remunerated on a scale which permits him to maintain a family. 